\title{
Does cancer affect marriage rates?
}

\author{
Astri Syse
}

Received: 20 May 2008 / Accepted: 3 July 2008 / Published online: 29 July 2008

(C) The Author(s) 2008

\begin{abstract}
Introduction Finding a life partner is of great importance for persons' life satisfaction, but cancer's potential impact on family life is not well described. Cancer's impact on marriage formation rates was therefore explored.

Method Data on the entire unmarried Norwegian population aged 17-44 in 1974-2001 ( $N=2.2$ million) come from the Cancer Registry and the Central Population Register. Marriage rates for 12,100 persons diagnosed with cancer were compared to marriage rates for otherwise similar persons using discrete-time hazard regression models.

Results Men with cancer had a marriage probability that was five percent higher (OR 1.05, CI 1.01-1.11) than cancer-free men. No cancer forms reduced men's marriage rates, and significantly elevated rates were seen after skin and testicular cancer (OR 1.16 and 1.11). Cancer did not impact significantly on women's overall marriage rate (OR 0.95 , CI 0.90-1.00), but pronounced deficiencies were seen after brain and breast cancer (OR 0.62 and 0.74). Skin cancer elevated women's marriage rate (OR 1.27). Male cancer survivors with children were more likely to marry than their female counterparts. Significant increases in cancer survivors' marriage rates were observed over time. Conclusion Marrying after cancer is more common today than previously, and only slight overall differences were observed in cancer survivors' marriage rates relative to those of the cancer-free population. However, while brain and breast cancer in women is associated with reduced marriage rates, testicular cancer is associated with increased
\end{abstract}

\footnotetext{
A. Syse $(\square)$

Cancer Registry of Norway,

Oslo, Norway

e-mail: astri.syse@medisin.uio.no
}

rates. The differences observed between common cancer forms in young adults deserve further exploration.

Implications for cancer survivors In general, marriage rates in survivors of most types of cancer are very similar to those in the population as a whole. Women with brain and breast cancer have lower marriage rates than their cancerfree counterparts. While it is necessary to identify exactly why this was observed, the information can alert those with these cancers to the potential impact on marriage and thus work to reduce the possible effect, if desired.

Keywords Cancer survivors · Marriage · Fertility .

Selection $\cdot$ Norway $\cdot$ Population-based

\section{Introduction}

Increased attention is now directed towards the long-term health and well-being of people living with a history of cancer. Although cancer incidence generally rises with age, many also get the disease as children, adolescents, or young adults. Finding a life partner has been shown to be of great importance for persons' life satisfaction [1], but cancer's potential impact on family life is not well described. Cancer's effects on marriage formation rates are therefore explored here.

Some studies suggest that people with poor health are less likely than others to enter marital unions and to have satisfactory and long-lasting relationships [2-5]. Cancer does not, however, necessarily have the same impact on family relations as other common illnesses. The development of a malignant disease is often particularly hard to predict and the lethality is high in many cases. In addition, such a disease may not be associated with the same stigma as those that more obviously result from people's life-style 
and lack of socioeconomic resources [6]. Cancer's impact on marriage formation rates has only been studied for survivors of childhood cancers. One recent British study described marital status in nearly 10,000 childhood cancer survivors, and found a marriage formation deficit in cancer survivors relative to the general population of around 9$18 \%$ for men and around $7-10 \%$ for women, and for brain cancer in particular [7]. Preliminary analyses from the US Childhood Cancer Survivor Study, including more than 10,000 survivors, show similar tendencies $[8,9]$, and detailed site-specific analyses on the effects of sarcomas, lymphomas, and leukemia show that cancer survivors are less likely to be married than their healthy siblings [10-13]. Marital status was only ascertained for around $60-70 \%$ of the two large childhood cohorts, and selection bias may be present. Earlier studies have, however, shown similar deficiencies in childhood cancer survivors' marriage probabilities, in particular for brain cancer survivors, but inconsistencies exist with regard to gender differences [14-16]. While studies using crude, unadjusted percentages indicate that marriage is as common for cancer survivors as it is for the general population [17-20], these studies did not explore the order of marriage formation and cancer illness.

Marriage formation deficits have been documented only after childhood cancer, and no studies have reported elevated marriage rates in childhood cancer survivors. A study of cancer's effects on marriage formation rates in an adult population and an exploration of possible mechanisms is thus warranted. Cancer illness is hypothesized to decrease marriage rates through (expectations of) lower fertility, reduced sexual activity, smaller emotional rewards from a potential relationship, a larger (expected) practical burden on the healthy potential partner, a possible lower educational level, and perhaps reduced income opportunities. Due to improvements in prognosis and an increased focus on long-term survival, it is hypothesized that marriage formation rates among cancer survivors become more similar to those of the general population over time.

\section{Material and method}

\section{Data}

Data from three sources were linked by means of the personal identification number assigned to everyone who has lived in Norway after 1960. The Norwegian Population Register provides information on date of birth, date of death or migration, dates of changes in marital status, and dates of birth of children. Educational levels were extracted from the population censuses of 1970, 1980, 1990, and 2001 . Information on cancer was drawn from the Cancer Registry of Norway, which has registered all cancer cases nationwide since 1953. Mandatory reporting from clinicians and pathologists, as well as death certificates, ensures completeness and high data quality on cancer form and stage at diagnosis [21]. Cancer survivors refer here to persons alive with a diagnosis of cancer. In line with standard practice, persons with basal cell carcinoma were not included among the cancer survivors [20]. The analyses were restricted to Norwegian men and women 17-44 years old in the period 1974-2001. Only first marriages and first cancer diagnoses were considered.

\section{Method}

Unmarried men and women were followed from age 17 or higher from 1974 onwards to determine the possible impact of cancer on their marriage formation rate. Marriage formation is defined as the legal union formed between two persons of different gender. A marriage has taken place if the marital status changes from 'unmarried' 1 year to 'married' the following year. As status as married is recorded January 1 the year following marriage, variables in the models were lagged 1 year. Persons who were unmarried in 1974 thus contributed a series of 1-year observations from 1974 or later until marriage, emigration, death, or end of follow-up. Discrete-time hazard regression models for marriage formation probabilities within the year were then estimated from the entire set of 1-year observations for all persons, men and women separately, using the Proc Logistic procedure in $\mathrm{SAS}^{\circledR} 9.1$ [22]. The statistical significance level was set at 5\%. Mathematically, the model is

$\log (p /(1-p))=\alpha_{0}+\alpha_{1} \mathbf{X}+\alpha_{2} \mathbf{D}$

where $p$ is the marriage probability within the 12-month interval, $\boldsymbol{D}$ is a vector of cancer disease characteristics, and $\boldsymbol{X}$ is a vector of other covariates. Several specifications of the cancer variable $\boldsymbol{D}$ were used. In one model, a distinction was made between no cancer and any cancer to explore overall effects. In other models, distinctions were made between childhood cancers $(<15$ years at diagnosis), cancers diagnosed less than 5 years earlier, and cancers diagnosed further back in time (Table 1). It was further differentiated between various common cancer types, 14 for men and 15 for women (Table 2), and also between localized and more advanced disease (Table 4). Attained age, educational level, parity, and calendar period may influence both the chance of getting cancer and, for completely different reasons, the marriage rate, and were therefore included in the $\boldsymbol{X}$ vector. These variables refer to the situation in the beginning of the year under consideration, except education, which is taken from the last previous census. 
Table 1 Effects of cancer, age, education, calendar period, and number of children on marriage probabilities in Norway in 1974-2001

\begin{tabular}{|c|c|c|c|c|c|c|}
\hline & \multicolumn{3}{|l|}{ Men } & \multicolumn{3}{|l|}{ Women } \\
\hline & Events/pyrs ${ }^{\mathrm{a}}$ & OR & $95 \% \mathrm{CI}$ & Events/pyrs & OR & $95 \% \mathrm{CI}$ \\
\hline \multicolumn{7}{|l|}{ Cancer diagnosis } \\
\hline No cancer & $503,000 / 13.3$ mill & 1.00 & (ref) & $511,286 / 10.0$ mill & 1.00 & (ref) \\
\hline Cancer $0-5$ years prior & $804 / 17,839$ & 1.12 & $1.04-1.20$ & $745 / 16,430$ & 0.99 & $0.92-1.07$ \\
\hline Cancer $>5$ years prior & $472 / 11,953$ & 1.05 & $0.95-1.15$ & $368 / 9,850$ & 0.96 & $0.86-1.06$ \\
\hline Childhood cancer $(<15 \text { years })^{\mathrm{b}}$ & $221 / 9,634$ & 0.89 & $0.78-1.02$ & $267 / 7,880$ & 0.85 & $0.75-0.96$ \\
\hline \multicolumn{7}{|l|}{ Attained age (years) } \\
\hline $17-19$ & $5,859 / 2.7$ mill & 0.07 & $0.07-0.07$ & $38,772 / 2.5$ mill & 0.23 & $0.23-0.24$ \\
\hline $20-24$ & $140,589 / 4.2$ mill & 1.00 & (ref) & $218,410 / 3.5$ mill & 1.00 & (ref) \\
\hline $25-29$ & 203,688/3.0 mill & 1.86 & $1.84-1.87$ & $166,720 / 2.1$ mill & 1.33 & $1.32-1.34$ \\
\hline $30-34$ & 104,147/1.8 mill & 1.50 & $1.49-1.52$ & 63,611/1.1 mill & 0.89 & $0.88-0.90$ \\
\hline $35-39$ & $36,930 / 1.0$ mill & 0.89 & $0.88-0.90$ & $19,254 / 605,418$ & 0.47 & $0.46-0.48$ \\
\hline $40-44$ & $13,284 / 640,054$ & 0.55 & $0.54-0.56$ & $5,899 / 362,775$ & 0.25 & $0.25-0.26$ \\
\hline \multicolumn{7}{|l|}{ Educational level } \\
\hline Low or unknown level & $46,549 / 2.8$ mill & 0.81 & $0.80-0.82$ & $98,763 / 2.4$ mill & 0.94 & $0.93-0.95$ \\
\hline Elementary level & $113,650 / 2.5$ mill & 1.00 & (ref) & $106,336 / 1.5$ mill & 1.00 & (ref) \\
\hline High school level & $245,110 / 5.9$ mill & 1.26 & $1.25-1.27$ & 206859/4.1 mill & 1.06 & $1.05-1.07$ \\
\hline Bachelor level & $76,106 / 1.8$ mill & 1.67 & $1.65-1.69$ & 87,464/1.9 mill & 1.26 & $1.24-1.27$ \\
\hline$\geq$ Master level & $23,082 / 431,298$ & 2.25 & $2.22-2.29$ & $13,244 / 272,280$ & 1.48 & $1.45-1.51$ \\
\hline \multicolumn{7}{|l|}{ Calendar period } \\
\hline 1974-1979 & 133,672/2.1 mill & 1.80 & $1.79-1.82$ & $134,358 / 1.4$ mill & 1.74 & $1.73-1.76$ \\
\hline 1980-1984 & $88,989 / 2.0$ mill & 1.00 & (ref) & $90,703 / 1.4$ mill & 1.00 & (ref) \\
\hline 1985-1989 & $80,585 / 2.3$ mill & 0.73 & $0.72-0.74$ & $82,877 / 1.7$ mill & 0.69 & $0.69-0.70$ \\
\hline 1990-1994 & 71,727/2.6 mill & 0.41 & $0.41-0.42$ & 74,108/2.0 mill & 0.43 & $0.42-0.43$ \\
\hline 1995-2001 & $129,524 / 4.4$ mill & 0.37 & $0.37-0.38$ & $130,620 / 3.6$ mill & 0.39 & $0.39-0.40$ \\
\hline \multicolumn{7}{|l|}{ Number of children (parity) } \\
\hline 0 & $373,869 / 11.7$ mill & 1.00 & (ref) & $373,778 / 8.3$ mill & 1.00 & (ref) \\
\hline 1 & 92,691/1.1 mill & 2.65 & $2.63-2.68$ & $96,135 / 1.3$ mill & 1.69 & $1.67-1.70$ \\
\hline 2 & $3,0937 / 412,382$ & 3.03 & $3.00-3.07$ & $35166 / 503421$ & 2.12 & $2.09-2.14$ \\
\hline 3 & $5,236 / 80,897$ & 3.09 & $3.00-3.18$ & $6,310 / 100,951$ & 2.29 & $2.23-2.35$ \\
\hline$\geq 4$ & $921 / 14151$ & 3.49 & $3.26-3.73$ & $934 / 17,091$ & 2.24 & $2.09-2.39$ \\
\hline Unknown (born <1935) & $843 / 36,023$ & 0.57 & $0.53-0.61$ & $343 / 16,797$ & 0.55 & $0.49-0.62$ \\
\hline
\end{tabular}

$O R$ odds ratio, $C I$ confidence interval

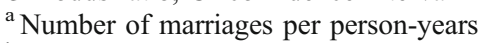

${ }^{\mathrm{b}}$ Any cancer diagnosed in childhood is included in this group, independent of time from diagnosis

Age affects both persons' chances of getting cancer and their marriage rates [23], whereas education, income, and parity are more problematic factors. On the one hand, cancer may operate through these factors in affecting the marriage rate. Cancer in childhood or during adolescent years may, for instance, reduce the chances of getting a higher education [24, 25], with long-term implications for marriage opportunities. Cancer illness may also interfere with work capability and income opportunities [26, 27], and a lower income is, in turn, likely to reduce the chances of marriage, especially for men. In principle, any effects of women's earnings depend on whether it is specialization [28] or pooling of resources [29, 30] that is most important for relationships. Current educational level is used throughout the analyses shown here, but the potential impact of the highest education obtained and current income was also explored. Cancer's effect on marriage formation rates did not differ with additional control for these two variables, and their effects are thus not shown. Parity was also included in all models, as having children increases partners' benefit from becoming married, compared to living alone or with another partner [28]. Because full birth histories are not available for people born before 1935, the parity variable has one category for 'unknown'. Excluding this group did not alter the results. Fertility has been shown to be reduced in cancer survivors, although improvements over time have been substantial [31], with potential implications for marriage formation probabilities.

On the other hand, education, income, and parity may be among the determinants of certain types of cancer. A high 
Table 2 Marriage probabilities by cancer form

\begin{tabular}{|c|c|c|c|c|c|c|c|c|}
\hline \multicolumn{5}{|l|}{ Men } & \multicolumn{4}{|l|}{ Women } \\
\hline Cancer form & Events/pyrs ${ }^{\mathrm{a}}$ & Number $^{\mathrm{b}}$ & OR & $95 \% \mathrm{CI}$ & Events/pyrs & Number & OR & $95 \% \mathrm{CI}$ \\
\hline No cancer & $503,000 / 13.3$ mill & 1.2 mill & 1.00 & (ref) & $511,286 / 10.2$ mill & 1.0 mill & 1.00 & (ref) \\
\hline Brain cancer & $161 / 5,164$ & 719 & 0.94 & $0.80-1.10$ & $104 / 3,781$ & 466 & 0.62 & $0.51-0.75$ \\
\hline Skin cancer & $201 / 4,329$ & 771 & 1.16 & $1.01-1.34$ & $352 / 6,202$ & 1042 & 1.27 & $1.14-1.42$ \\
\hline Hodgkin disease & $164 / 3,777$ & 519 & 1.08 & $0.87-1.34$ & $101 / 2,281$ & 322 & 0.95 & $0.77-1.16$ \\
\hline Leukemia & $78 / 2,982$ & 517 & 1.08 & $0.86-1.36$ & $81 / 2,170$ & 355 & 1.03 & $0.82-1.28$ \\
\hline Endocrine cancer & $45 / 1,217$ & 181 & 1.04 & $0.77-1.40$ & $130 / 2,683$ & 377 & 0.99 & $0.83-1.19$ \\
\hline Non-Hodgkin disease $\mathrm{e}^{\mathrm{c}}$ & $89 / 2,284$ & 379 & 1.06 & $0.90-1.24$ & $44 / 978$ & 181 & 1.10 & $0.81-1.49$ \\
\hline Renal/bladder cancer & $43 / 1,491$ & 218 & 0.92 & $0.68-1.25$ & $31 / 907$ & 112 & 0.79 & $0.55-1.13$ \\
\hline Bone cancer & $42 / 1,374$ & 216 & 0.86 & $0.63-1.17$ & $31 / 822$ & 122 & 0.79 & $0.55-1.13$ \\
\hline Colorectal cancer & $46 / 1,163$ & 305 & 1.16 & $0.86-1.57$ & $29 / 810$ & 208 & 1.03 & $0.71-1.50$ \\
\hline Soft tissue cancer & $33 / 879$ & 126 & 1.07 & $0.76-1.53$ & $40 / 876$ & 115 & 0.85 & $0.61-1.17$ \\
\hline Head-and-neck cancer & $23 / 662$ & 147 & 0.87 & $0.57-1.32$ & $21 / 592$ & 99 & 0.79 & $0.51-1.23$ \\
\hline Lung cancer & $18 / 418$ & 101 & 1.12 & $0.69-1.82$ & $12 / 270$ & 59 & 1.06 & $0.59-1.90$ \\
\hline Testicular cancer & $526 / 1,2583$ & 1961 & 1.11 & $1.01-1.21$ & N/A & N/A & N/A & N/A \\
\hline Cervical/uterine cancer & N/A & N/A & N/A & N/A & $157 / 4,206$ & 795 & 0.92 & $0.79-1.09$ \\
\hline Ovarian cancer & N/A & N/A & N/A & N/A & $152 / 3,851$ & 616 & 0.93 & $0.79-1.09$ \\
\hline Breast cancer & N/A & N/A & N/A & N/A & $65 / 2,929$ & 749 & 0.74 & $0.58-0.95$ \\
\hline Other or unknown & $28 / 1,103$ & 160 & 0.74 & $0.50-1.08$ & $30 / 802$ & 122 & 0.82 & $0.57-1.18$ \\
\hline
\end{tabular}

Marriage probabilities adjusted for age, education, calendar period, and number of children (Table 1)

$O R$ odds ratio, $C I$ confidence interval

${ }^{a}$ Number of marriages per person-years

${ }^{\mathrm{b}}$ Persons

${ }^{\mathrm{c}}$ Including lymphoma nos (not otherwise specified)

level of socioeconomic resources, for instance represented by many years of schooling, will increase the chances of developing breast cancer and melanoma, while reducing the chance of lung, stomach, and cervical cancer [32]. Furthermore, fertility is widely assumed to affect the chance of developing breast, endometrial, and ovarian cancer, with the risk of cancer declining with increasing parity, while the inverse is true for cervical cancer development [32].

Lately, births out of wedlock have become increasingly more common in Norway as in most other developed countries [33], and the earlier causal relation between marriage and fertility is currently challenged. Some models were therefore set up to explore the complex relationship between childbearing and marriage, and the differential effects of cancer depending on whether persons were childless, had children prior to their cancer diagnosis, or had had any children after their cancer diagnosis (Table 5).

Increases in cancer incidence and improvements in prognosis, along with changes in marriage formation rates over time, necessitated the inclusion of calendar period. Additional models including an interaction term between calendar year as a continuous variable and various disease variables were also estimated to assess changes over time in the effect of cancer on marriage rates. Also analyses stratified on educational level (low education comprising persons with elementary schooling or less vs. higher education) and calendar period ( $<1990$ vs. 1990 and later) to look for possible differential effects of cancer in subgroups of cancer survivors were undertaken.

\section{Results}

The size of the material

A total of 2.24 million unmarried Norwegian men and women 17-44 years old in the period 1974-2001 were included in this study. The 1,195,676 men and 1,048,176 women contributed each an average of 11.1 and 9.7 personyears. The total number of marriages was 504,497 among men and 512,666 among women. Included in these numbers were 6,320 male cancer survivors for whom 1,497 marriages were registered, while 1,380 marriages were registered among 5,740 female cancer survivors. Around $15 \%$ of the cancer survivors were diagnosed during childhood.

\section{Overall effects}

Unmarried men with a cancer of any type, diagnosed any time, had a marriage formation rate that was $5 \%$ higher [odds ratio (OR) 1.05, 95\% confidence interval (CI) 1.01-1.11] than that of otherwise similar men without a cancer 
diagnosis. Among women, cancer was associated with a 5\% lower marriage formation rate (OR 0.95, CI 0.90-1.00). Excluding childhood cancer survivors did not change the estimate significantly for women (OR 0.99, CI 0.93-1.05), but increased it slightly for men (OR 1.12, CI 1.06-1.18). Estimates from a model including illness duration are shown in Table 1, along with the effect of the other variables in the model. Men with a relatively recent cancer diagnosis had higher marriage rates than those with cancers diagnosed further back in time. Women diagnosed during childhood had a $15 \%$ lower marriage probability than both the general population and other women with a history of cancer.

\section{Site-specific effects}

The effects vary somewhat across cancer sites (Table 2). No cancer type had a significant adverse effect on marriage probability in men. A statistically significant increase in the marriage probability of $16 \%$ for men and $27 \%$ for women diagnosed with skin cancer was observed, and a likewise $11 \%$ increase for men with testicular cancer. Among women, survivors of brain cancer experienced a $38 \%$ reduction in their marriage probability. No effect was seen for male brain cancer. Breast cancer was associated with a significant $26 \%$ decrease in women's marriage probability, while no significant reduction was observed for gynecological cancers. Excluding cancer survivors diagnosed during childhood made no impact on any of the overall site-specific cancer estimates among either gender. Among childhood survivors, only brain (OR 0.73, CI 0.56-0.95) and renal and bladder cancer (OR 0.62, CI 0.39-0.99) in women gave statistically significant results.

\section{Effects of time}

Younger persons today cohabitate for an increasing period of time and thus postpone or defer marriage altogether [33-
35]. Childbirths have become more detached from marriage [36], but the mean childbearing age has increased markedly [36]. As cancer increases quite sharply with age, this has resulted in an increase in the number of unmarried and/or childless cancer survivors. An interaction term between cancer and calendar year revealed that cancer survivors' marriage probabilities have increased significantly from 1974 until today. Compared to the overall, cancer-free population, the marriage probability among male cancer survivors was predicted to 0.88 in $1974,1.04$ in 1990 , and 1.17 in 2001. Among females, the corresponding predicted estimates were $0.60,0.91$, and 1.21. Analyses stratified on early vs. late calendar period gave fairly similar but less pronounced estimates for both men and women (Table 3).

No cancer types reduce the marriage probabilities today compared to earlier. An interaction term between the specific cancer types and calendar year revealed that men with skin and lung cancer have a significantly increased marriage probability today compared to earlier, with ORs of 0.85 and 0.40 in 1974 , and correspondingly 1.46 and 2.03 in 2001 . Among women, significant increases with time were seen for several cancer types. The respective ORs in 1974 vs. 2001 were 0.28 vs. 0.92 for brain cancer, 0.37 vs. 1.07 for breast cancer, 0.47 vs. 1.30 for gynecological cancers, 0.68 vs. 1.30 for endocrine cancers, and 0.93 vs. 1.52 for skin cancer. Sitespecific analyses stratified on calendar period gave fairly similar results, with the most pronounced effects for skin cancer in both genders, and for leukemia and gynecological cancers in women (not shown). The marriage rate among female brain cancer survivors, although improving over time, remains below that of the general population (OR $0.56, \mathrm{CI}$ 0.33-0.94 vs. OR 0.71, CI 0.55-0.90).

The importance of cancer stage and prognosis

Among men, the marriage formation rate is significantly increased for persons with localized cancers (Table 4). No

Table 3 Marriage probabilities stratified on calendar period

\begin{tabular}{|c|c|c|c|c|c|c|c|c|}
\hline & \multicolumn{4}{|l|}{ Men } & \multicolumn{4}{|c|}{ Women } \\
\hline & \multicolumn{2}{|c|}{$<1990$} & \multicolumn{2}{|c|}{$\geq 1990$} & \multicolumn{2}{|c|}{$<1990$} & \multicolumn{2}{|c|}{$\geq 1990$} \\
\hline & OR & $95 \% \mathrm{CI}$ & OR & $95 \% \mathrm{CI}$ & OR & $95 \% \mathrm{CI}$ & OR & $95 \% \mathrm{CI}$ \\
\hline No cancer & 1.00 & (ref) & 1.00 & (ref) & 1.00 & (ref) & 1.00 & (ref) \\
\hline Cancer, overall & 0.91 & $0.84-0.99$ & 1.05 & $0.98-1.12$ & 0.77 & $0.70-0.84$ & 1.01 & $0.95-1.08$ \\
\hline Cancer $0-5$ years prior & 1.00 & $0.90-1.12$ & 1.13 & $1.03-1.24$ & 0.79 & $0.70-0.90$ & 1.08 & $0.99-1.19$ \\
\hline Cancer $>5$ years prior & 0.81 & $0.68-0.98$ & 1.02 & $0.91-1.13$ & 0.85 & $0.70-1.03$ & 0.93 & $0.82-1.05$ \\
\hline Childhood cancer $(<15 \text { years })^{\mathrm{a}}$ & 0.78 & $0.63-0.96$ & 0.92 & $0.77-1.09$ & 0.65 & $0.53-0.80$ & 0.96 & $0.82-1.12$ \\
\hline
\end{tabular}

Marriage probabilities adjusted for age, education, calendar period, and number of children (Table 1)

$O R$ odds ratio, $C I$ confidence interval

${ }^{a}$ Any cancer diagnosed in childhood is included in this group, independent of time from diagnosis 
Table 4 Marriage probabilities by cancer stage

\begin{tabular}{|c|c|c|c|c|c|c|}
\hline \multirow[b]{2}{*}{ Cancer stage } & \multicolumn{3}{|l|}{ Men } & \multicolumn{3}{|l|}{ Women } \\
\hline & Events/pyrs ${ }^{\mathrm{a}}$ & OR & $95 \% \mathrm{CI}$ & Events/pyrs & OR & $95 \% \mathrm{CI}$ \\
\hline No cancer & $503,000 / 13.3$ mill & 1.00 & (ref) & $511,286 / 10.2$ mill & 1.00 & (ref) \\
\hline Local cancer & $701 / 16,934$ & 1.10 & $1.02-1.19$ & $862 / 19,633$ & 1.02 & $0.95-1.10$ \\
\hline Regional cancer & $238 / 6,265$ & 1.01 & $0.89-1.15$ & $144 / 3,895$ & 0.90 & $0.76-1.07$ \\
\hline Metastatic cancer & $41 / 1,113$ & 1.28 & $0.93-1.75$ & $18 / 663$ & 0.86 & $0.53-1.37$ \\
\hline Stage unknown & 25/907 & 0.77 & $0.51-1.14$ & $26 / 759$ & 0.75 & $0.50-1.11$ \\
\hline Blood, lymph ${ }^{\mathrm{b}}$ and brain cancer & $492 / 14,207$ & 1.02 & $0.94-1.12$ & $330 / 9,210$ & 0.84 & $0.75-0.93$ \\
\hline
\end{tabular}

Marriage probabilities adjusted for age, education, calendar period, and number of children (Table 1)

$O R$ odds ratio, $C I$ confidence interval

${ }^{a}$ Number of marriages per person-years

${ }^{\mathrm{b}}$ Stage not recorded

effect is evident for more advanced disease. Among women, no significant effect of stage is observed, although there is a nonsignificant trend in the point estimates suggesting that marriage becomes less likely with more advanced disease.

The influence of fertility and education

Analyses stratified on the presence or absence of children showed that the effect of cancer on the probability of marriage differed among childless persons and persons who had at least one child. The marriage probability of childless men with cancer was equal to that of the cancer-free, childless population (OR 1.00, CI 0.94-1.06), while it was significantly increased for male parents with cancer relative to male cancer-free parents (OR 1.19, CI 1.09-1.29). Female parents with cancer had, however, a marriage probability equal to that of the cancer-free population with children (OR 0.98, CI 0.90-1.07). A closer look at the order of appearance of children and cancer showed that it was mainly the children born after the cancer diagnosis that elevated the marriage rates, and that childless women with cancer turned out to have an $8 \%$ lower marriage rate than other childless women (Table 5).
The marriage probability of childless men with brain cancer was significantly reduced (OR 0.78 , CI $0.64-0.95$ ), while it was significantly increased for men with children (OR 1.84, CI 1.40-2.43). The same increase in marriage probabilities was also seen for male parents with a history of leukemia (OR 1.67, CI 1.16-2.39) or testicular cancer (OR 1.18, CI 1.02-1.37). Among women with children, skin cancer was the only cancer type that increased the marriage probability (OR 1.30 , CI $1.10-1.55$ ). Cervical cancer, however, resulted in a significantly reduced marriage probability for these women (OR 0.73, CI 0.59-0.92). This was the only cancer type among parents that actually reduced the marriage probability.

Most cancer estimates did not change significantly when educational level was excluded (not shown). Analyses stratified on educational level, however, showed that while lower educated men with a history of cancer had a slight but statistically significant elevated marriage probability (OR 1.10, CI 1.02-1.19), men with cancer and higher education had a marriage probability equal to that of the cancer-free population (OR 1.05, CI0.98-1.13). For women, the tendency was opposite: Lower educated women with a history of cancer had a reduced marriage probability compared to women with higher education, and also

Table 5 Marriage probabilities by cancer and parenthood

\begin{tabular}{|c|c|c|c|c|c|c|}
\hline & \multicolumn{3}{|l|}{ Men } & \multicolumn{3}{|l|}{ Women } \\
\hline & Events/pyrs ${ }^{\mathrm{a}}$ & OR & $95 \% \mathrm{CI}$ & Events/pyrs & OR & $95 \% \mathrm{CI}$ \\
\hline No cancer, no children & $373,680 / 11.7$ mill & 1.00 & (ref) & $373,240 / 8.3$ mill & 1.00 & (ref) \\
\hline No cancer, child(ren) & 129,320/1.6 mill & 2.75 & $2.73-2.77$ & 138,046/1.9 mill & 1.79 & $1.77-1.80$ \\
\hline Cancer, no children & $1,032 / 33,546$ & 1.00 & $0.94-1.06$ & $881 / 24,473$ & 0.92 & $0.86-0.98$ \\
\hline Cancer, child(ren) before diagnosis & $158 / 2,384$ & 2.89 & $2.45-3.40$ & $195 / 5,635$ & 1.27 & $1.10-1.47$ \\
\hline Cancer, child(ren) after diagnosis & $307 / 3,496$ & 3.57 & $3.17-4.02$ & $304 / 4,052$ & 2.37 & $2.11-2.67$ \\
\hline
\end{tabular}

Marriage probabilities adjusted for age, education, calendar period, and number of children (Table 1)

$O R$ odds ratio, $C I$ confidence interval

${ }^{a}$ Number of marriages per person-years 
compared to the otherwise similar cancer-free population (OR 0.86, CI 0.79-0.93 vs. OR 1.05, CI 0.97-1.13). Sitespecific analyses showed that testicular cancer was primarily responsible for the elevated marriage probability among lower educated men (OR 1.20, CI 1.04-1.38), while brain cancer was mainly responsible for the deficiency observed among lower educated women (OR 0.57, CI 0.43-0.76). Highly educated women with leukemia were the only women, in addition to those with skin cancer, who experienced a significantly elevated marriage probability (OR 1.48, CI 1.12-1.93 and OR 1.26, CI 1.10-1.45, respectively), while marriage rates were markedly reduced among highly educated women after breast cancer (OR 0.72, CI0.52-0.98).

\section{Discussion}

Overall, marriage rates are not reduced as hypothesized. Marriage formation rates in men tend to increase, whereas the marriage-reducing effects dominate or balance the opposite tendency in women. Cancer in women thus appears to be more harmful for marriage formation than cancer in men, but is mainly a consequence of the strong negative impact of female childhood cancer. This gender difference is disproportionate to findings in some larger childhood cancer studies [7, 8, 10, 15], but not all [16, 37]. The effects of the various cancer types are surprisingly inconsistent. Whereas skin cancer in both men and women results in elevated marriage rates, brain cancer has a negative impact only in women. This is in contrast to the findings of others $[7,8]$. Breast and testicular cancer are gender-specific cancer types, closely connected to sexuality and reproduction. Noteworthy, these cancer types result in lower marriage rates in women and elevated rates in men.

Our view on cancer is changing quit rapidly: Treatment regiments have become less aggressive over the last decades, both as a result of technological innovations and an increased awareness and recognition of the need to maximize a persons' quality of life after cancer [38]. For many localized cancers today, treatment may actually be presumed to be physically nearly non-afflicting. For more advanced cancers, however, treatment may impact physical, psychological, and social functioning. Thus, marriage rates in cancer survivors do not necessarily follow the same trend over time as those of the general population, which is indeed observed here.

\section{Theoretical framework}

According to economic-demographic theory, a couple will marry if they expect that living together will be better than living alone, taking both economic and other advantages into account, and thinking that they cannot find a better partner without making substantial sacrifices [28, 29]. Consensual unions are, however, common in Norway. Whether persons in consensual unions eventually marry or not depends on both the quality of the relationship and on the practical, economic or emotional advantages of being formally married [35]. Childbearing and union formations are, of course, deeply intertwined. The possibility of having children contributes to the advantage of being in a relationship, and once a child is born, the value of the relationship is particularly high compared to being single or in another relationship. Thus, among those who are childless and single, the chance of marrying depends on a number of factors, including their desire for a child and their (perceived) ability to conceive. Cohabitants are apparently conscious about the strong advantages of their relationship, and marriage may be a smaller step away. Childbearing desires and opportunities will also influence their chance of marriage. Those who already have a child in Norway are typically cohabitants, and their chance of marrying may to a larger extent depend on aspects other than those related to childbearing [35]. The advantages persons require for a marriage to occur, however, vary both between persons and over time [30]. Most commonly, however, 'like marries like', more formally referred to as positive assortative mating or homogamy [28, 29, 39]. This implies that persons with similar intelligence, education, personality, religion, health, and/or other common traits marry each other, thus encompassing cancer illness and illness consequences as a possible negative determinant in marriage formation.

An evaluation of possible mechanisms in light of results

Encountering and 'conquering' cancer has been suggested to influence life priorities and increase family orientation in both cancer patients and potential or existing partners [40]. Persons who are single when getting cancer, may be more inclined to find a partner and thus direct more effort into the search, or alternatively accept a person of lower 'standard' compared to previously $[28,29]$. The quality of an existing relationship may be enhanced when one partner becomes ill, as cancer may be considered a joint experience, perhaps especially if the relationship was good at the outset [41]. Cancer illness may also affect the quality of the relationship adversely, as poor health may lead to behavioral and mood changes. Various physical, psychological and social effects of cancer will inevitably interfere with persons' abilities to undertake their usual chores and obligations in relationships, either temporarily or permanently [42, 43]. Cancer may, however, make both the ill and the healthy person more inclined to formalize their relationship, regardless of its' quality. A recent Norwegian study suggests that female 
cohabitants have stronger preferences for marriage than males have [44]. If cancer makes younger men more inclined to marry compared to other, healthy men, this could increase their marriage rates. This may explain the elevated marriage probability observed after for instance testicular cancer.

Cancer has been hypothesized to influence emotional and physical intimacy, sexuality and fertility, and thereby marriage rates [28, 30, 45-47]. Men may for instance experience erectile and ejaculatory dysfunction related to damage to the autonomic nervous system [47], and although hormonal impairment is less common, some men with cancer may experience a general decrease in libido [47]. Among women, direct effects of radiation fibrosis or surgical scar tissue may cause pain with sexual activity [45]. In addition, fatigue, chronic weakness, and an altered physical appearance due to e.g. a stoma, limb amputation, or mastectomy, has been reported to negatively affect sexuality [46]. Cancer has also been found to reduce birth rates with an overall effect of about $25 \%$ both in Norway and other countries, probably because of lower fecundity as well as weaker fertility desires [31]. The strongest effects have been seen for women with gynecological cancers and men with testicular cancer, though the latter effects have diminished over time as a result of cryopreservation of semen and in vitro fertilization [48]. How changes in intimacy or sexuality will affect marriage rates is not clear. It may be more attractive for a person with cancer to remain in a stable relationship rather than to continue dating. A potential partner may, however, view actual or future problems related to intimacy and/or fertility negatively. Overall, declines in fertility were expected to impact more negatively in women than men, as having children has been theorized to be particularly important for females' roles in society [28]. Men have, traditionally, been considered breadwinners, while women have been expected to perform a larger share of domestic activities, including care. This pattern may on the one hand result in men with cancer being less attractive due to their potential reduced income capacity. On the other hand, some have suggested that women may be prepared to care for men, but that men may lack experience and practice in caring for women, and thus perhaps are less willing to take on responsibility for a sick partner [49]. Potential differences will, however, most likely become weaker over time, as men and women perform more similar roles in society [30].

The gender differences observed are in part in line with the predictions. Whereas breast cancer significantly reduced women's marriage probability, no effect was observed for gynecological cancers. This latter finding may suggest that fertility expectations do not influence marriage formation rates strongly in either gender. Breast cancer is in general quite visible, while testicular cancer and gynecological cancers may be considered more private diseases. Brain cancer can be extremely debilitating and alter both physical, psychological, and social functioning [38]. It may thus significantly interfere with the ability to fill the role of a life partner. Low marriage rates could thus be expected for both genders. Men with brain cancer, however, appear to have the same marriage probability as cancer-free men. Studies suggest that the effect of radiation treatment may be more severe for female brain cancer survivors [24], and that psychosocial outcomes may be worse [50]. Social explanations tied to gender roles are, however, also possible [28]. Prognosis is in general more favorable for testicular cancer and gynecological cancers compared to for instance breast and brain cancer and may also play a role. Expectations of outcomes with regard to both morbidity and mortality may impact the decision to marry, as may be implied from the estimates provided on effects of disease spread: Men with good or poor prognosis appear to have a higher likelihood of marriage than those with a fair outlook, whereas women's marriage rates decline with increasing morbidity.

Unmarried parents, either cancer survivors or their partners, may find formalizing bonds through marriage to be beneficial for both practical and economic reasons, for themselves as well as for their children. Norwegian legislation on economic matters in case of parental disability or death is less ambiguous for married couples than for single persons, persons in relationships, or cohabitants, and may thus motivate marriage. A strong positive effect of cancer is indeed seen for male parents' marriage probability, while no corresponding effect is seen for female parents. A possible explanation for the gender differences observed may be that men still continue to be the primary breadwinners in Norway, and that couples want to secure an independent economic situation if possible, in particular in the uncertain initial phase or during the most critical periods. This is also valid for brain cancer survivors: Male parents and those who married very shortly after diagnosis are responsible for the increased marriage rate. Analyses stratified on educational level, however, suggested that it was the lower and not higher educated male cancer survivors that had the highest marriage formation rates. On the one hand, this was somewhat surprising, as 'breadwinners' were expected to secure their families through marriage to the greatest extent. On the other hand, lower educated men are in general married to women with lower educations and incomes [39], and these families may be in a particularly vulnerable situation thus opting for marriage.

One limitation of the current study is that it only considers marriage formation. Cohabitation has become increasingly common in Norway as in most other developed countries [33, 34], and also these transitions should ideally have been modeled in order to determine whether the chance of forming any relationship, not only marriage, 
is affected by cancer. Unfortunately, reliable data on cohabitation are not available.

\section{Conclusion}

How cancer affects potential interpersonal relationships, and thus the prospects of becoming married, is an important question for those concerned with cancer patients' welfare, but also of interest from a more general family-behavior perspective. One could expect a stressor such as cancer to reduce the quality of both potential and existing relationships, and thus contribute to lower marriage formation rates. Other factors more than counterbalance such effects, and marrying after cancer is more common today than previously. With regards to possible mechanisms, it appears that the potentially harmful effects through lower fertility expectations, lower educational achievements, and reduced incomes are minor. Only slight effects are observed for the specific cancer types, with the exception of brain and breast cancer in women. Persons experiencing these diseases thus experience a greater burden: In addition to uncertainties and symptom burdens that can accompany these types of cancers depending on extent and other features of the illness as well as exposure to treatments, they run a lower chance of finding a life partner. Testicular cancer, on the other hand, appears to increase men's chances of marriage. This gender difference in the most common cancer types in young adults deserves further exploration.

Acknowledgements I am grateful for the extensive help I received from Øystein Kravdal in data analyses, interpretation, and manuscript drafting. This research was supported by a grant from the Norwegian Foundation of Health and Rehabilitation, through the Norwegian Cancer Society. A licensure to link data was provided by the Norwegian Data Inspectorate.

Open Access This article is distributed under the terms of the Creative Commons Attribution Noncommercial License which permits any noncommercial use, distribution, and reproduction in any medium, provided the original author(s) and source are credited.

\section{References}

1. Cairns RB, Elder GH, Costello J. Developmental science. Cambridge: Cambridge University Press; 1996.

2. Lillard LA, Panis CW. Marital status and mortality: the role of health. Demography 1996;33 3:313-27. doi:10.2307/2061764.

3. Joung IM, van de Mheen HD, Stronks K, van Poppel FW, Mackenbach JP. A longitudinal study of health selection in marital transitions. Soc Sci Med 1998;46 3:425-35. doi:10.1016/S02779536(97)00186-X.

4. Waldron I, Hughes ME, Brooks TL. Marriage protection and marriage selection - prospective evidence for reciprocal effects of marital status and health. Soc Sci Med 1996;43 1:113-23. doi:10.1016/0277-9536(95)00347-9.
5. Blekesaune M, Øverbye E, Romøren TI. Health selection in marital transitions: evidence from administrative data. NOVA 2003;22 03:34-52.

6. Goldberg RJ, Cullen LO. Factors important to psychosocial adjustment to cancer: a review of the evidence. Soc Sci Med 1985;20 8:803-7. doi:10.1016/0277-9536(85)90334-X.

7. Frobisher C, Lancashire ER, Winter DL, Jenkinson HC, Hawkins MM. Long-term population-based marriage rates among adult survivors of childhood cancer in Britain. Int J Cancer 2007;121 4:846-55. doi:10.1002/ijc.22742.

8. Rauck AM, Green DM, Yasui Y, Mertens A, Robison LL. Marriage in the survivors of childhood cancer: a preliminary description from the Childhood Cancer Survivor Study. Med Pediatr Oncol 1999;33 1:60-3. doi:10.1002/(SICI)1096-911X (199907)33:1<60::AID-MPO11>3.0.CO;2-H.

9. Ness KK, Gurney JG, Zeltzer LK, Leisenring W, Mulrooney DA, Nathan PC, et al. The impact of limitations in physical, executive, and emotional function on health-related quality of life among adult survivors of childhood cancer: a report from the Childhood Cancer Survivor Study. Arch of Phys Med Rehabil 2008;89 1:128-36. doi:10.1016/j.apmr.2007.08.123.

10. Nagarajan R, Neglia JP, Clohisy DR, Yasui Y, Greenberg M, Hudson M, et al. Education, employment, insurance, and marital status among 694 survivors of pediatric lower extremity bone tumors: a report from the childhood cancer survivor study. Cancer 2003;97 10:2554-64. doi:10.1002/cncr.11363.

11. Zebrack BJ, Zeltzer LK, Whitton J, Mertens AC, Odom L, Berkow R, et al. Psychological outcomes in long-term survivors of childhood leukemia, Hodgkin's disease, and nonHodgkin's lymphoma: a report from the Childhood Cancer Survivor Study. Pediatrics 2002;110 1 Pt 1:42-52. doi:10.1542/ peds.110.1.42.

12. Mulrooney DA, Dover DC, Li S, Yasui Y, Ness KK, Mertens AC, et al. Twenty years of follow-up among survivors of childhood and young adult acute myeloid leukemia: a report from the Childhood Cancer Survivor Study. Cancer 2008;112 9:2071-9. doi:10.1002/cncr.23405.

13. Punyko JA, Gurney JG, Scott BK, Hayashi RJ, Hudson MM, Liu Y, et al. Physical impairment and social adaptation in adult survivors of childhood and adolescent rhabdomyosarcoma: a report from the Childhood Cancer Survivors Study. Psycho-Oncol 2007;16 1:26-37. doi:10.1002/pon.1072.

14. Byrne J, Fears TR, Steinhorn SC, Mulvihill JJ, Connelly RR, Austin DF, et al. Marriage and divorce after childhood and adolescent cancer. J Am Med Assoc 1989;262 19:2693-9. doi:10. 1001/jama.262.19.2693.

15. Langeveld NE, Ubbink MC, Last BF, Grootenhuis MA, Voute PA, de Haan RJ. Educational achievement, employment and living situation in long-term young adult survivors of childhood cancer in the Netherlands. Psycho-Oncol 2003;12 3:213-25. doi:10. 1002/pon.628.

16. Green DM, Zevon MA, Hall B. Achievement of life goals by adult survivors of modern treatment for childhood cancer. Cancer 1991;67 1:206-13. doi:10.1002/1097-0142(19910101)67:1<206:: AID-CNCR2820670134>3.0.CO;2-2.

17. Joly F, Heron JF, Kalusinski L, Bottet P, Brune D, Allouache N, et al. Quality of life in long-term survivors of testicular cancer: a population-based case-control study. J Clin Oncol 2002;20 1:7380. doi:10.1200/JCO.20.1.73.

18. Joly F, Henry-Amar M, Arveux P, Reman O, Tanguy A, Peny AM, et al. Late psychosocial sequelae in Hodgkin's disease survivors: a French population-based case-control study. J Clin Oncol 1996;14 9:2444-53.

19. Yabroff KR, Lawrence WF, Clauser S, Davis WW, Brown ML. Burden of illness in cancer survivors: findings from a populationbased national sample. J Natl Cancer Inst 2004;96 17:1322-30. 
20. Hewitt M, Rowland JH, Yancik R. Cancer survivors in the United States: age, health, and disability. J Gerontol Ser A, Biol Sci Med Sci 2003;58 1:82-91.

21. Cancer in Norway 2006. Oslo: Kreftregisteret. www.kreftregisteret. no; 2007.

22. Allison PD. Survival analysis using SASÒ: a practical guide. Cary, NC: SAS Institute Inc.; 1995.

23. Booth A, Edwards JN. Age at marriage and marital instability. J Marriage Fam 1985;47 1:67-75. doi:10.2307/352069.

24. Lahteenmaki PM, Harila-Saari A, Pukkala EI, Kyyronen P, Salmi TT, Sankila R. Scholastic achievements of children with brain tumors at the end of comprehensive education: a nationwide, register-based study. Neurology 2007;69 3:296-305. doi:10.1212/ 01.wnl.0000265816.44697.b4.

25. Harila-Saari AH, Lahteenmaki PM, Pukkala E, Kyyronen P, Lanning M, Sankila R. Scholastic achievements of childhood leukemia patients: a nationwide, register-based study. J Clin Oncol 2007;25 23:3518-24. doi:10.1200/JCO.2006.09.4987.

26. Bradley CJ, Bednarek HL. Employment patterns of long-term cancer survivors. Psycho-Oncol 2002;11 3:188-98. doi:10.1002/pon.544.

27. Syse A, Tretli S, Kravdal O. Cancer's impact on employment and earnings - a population-based study from Norway. J Cancer Survivorship 2008. doi:10.1007/s11764-008-0053-2.

28. Becker GS. A treatise on the family. Cambridge, MA: Harvard University Press; 1991.

29. Oppenheimer VK. A theory of marriage timing. Am J Sociol 1988;94 3:563-91. doi:10.1086/229030.

30. Oppenheimer VK. The continuing importance of men's economic position in marriage formation. In: Waite LJ, Bachrach C, Hindin MJ, Thomsom E, Thornton A, editors. The ties that bind. Perspectives on marriage and cohabitation. New York: Aldine de Gruyter; 2000.

31. Syse A, Kravdal O, Tretli S. Parenthood after cancer-a population-based study. Psycho-Oncol 2007;16 10:920-7. doi:10.1002/pon.1154.

32. Colditz G, DeJong W, Hunter D, Trichopoulos D, Willett W. Harvard report on cancer prevention. Volume 1: causes of human cancer. Cancer Causes \& Control 1996;7 Suppl 1:S3-59. doi:10.1007/BF00051890.

33. Noack T. Cohabitation in Norway: an accepted and gradually more regulated way of living. Int J Law Policy Fam 2001;15 1:102-17. doi:10.1093/lawfam/15.1.102.

34. Waite LJ, Bachrach C, Hindin MJ, Thomsom E, Thornton A. The ties that bind. Perspectives on marriage and cohabitation. New York: Aldine de Gruyter; 2000.

35. Kravdal O. Does marriage require a stronger economic underpinning than informal cohabitation. Popul Stud 1999;53 1:63-80. doi: $10.1080 / 00324720308067$.
36. Statistics Norway. ww.ssb.no. 10-4-2008.

37. Pui CH, Cheng C, Leung W, Rai SN, Rivera GK, Sandlund JT, et al. Extended follow-up of long-term survivors of childhood acute lymphoblastic leukemia. N Eng J Med 2003;349 7:640-9. doi:10.1056/NEJMoa035091.

38. Demark-Wahnefried W, Aziz NM, Rowland JH, Pinto BM. Riding the crest of the teachable moment: promoting long-term health after the diagnosis of cancer. J Clin Oncol 2005;23 24:5814-30. doi:10.1200/JCO.2005.01.230.

39. Birkelund GE, Heldal J. Who marries whom? Educational homogamy in Norway. Demographic Research 2003;8 1:1-30.

40. Manne S. Cancer in the marital context: a review of the literature. Cancer Investig 1998;16 3:188-202. doi:10.3109/073579098 09050036.

41. Northouse LL, Templin T, Mood D, Oberst M. Couples' adjustment to breast cancer and benign breast disease: a longitudinal analysis. Psycho-Oncol 1998;7 1:37-48. doi:10.1002/(SICI)1099-1611 (199801/02)7:1<37::AID-PON314>3.0.CO;2-\#.

42. Booth A, Johnson DR. Declining health and marital quality. J Marriage Fam 1994;56 2:218-23. doi:10.2307/352716.

43. Schroevers MJ, Ranchor AV, Sanderman R. The role of age at the onset of cancer in relation to survivors' long-term adjustment: a controlled comparison over an eight-year period. Psycho-Oncol 2004;13 10:740-52. doi:10.1002/pon.780.

44. Reneflot A. A gender perspective on preferences for marriage among cohabitating couples. Demographic Research 2006;15 $10: 311-28$.

45. Bergmark K, Lundqvist E, Dickman PW, Henningsohn L, Steineck G. Vaginal changes and sexuality in women with a history of cervical cancer. N Engl J Med 1999;340 18:1383-9. doi:10.1056/NEJM199905063401802.

46. Schover LR. Motivation for parenthood after cancer: a review. J Natl Cancer Inst Monogr. 2005;(34):2-5. doi:10.1093/jncimono graphs/lgi010.

47. Nazareth I, Lewin J, King M. Sexual dysfunction after treatment for testicular cancer: a systematic review. J Psychosom Res 2001;51 6:735-43. doi:10.1016/S0022-3999(01)00282-3.

48. Schover LR. Sexuality and fertility after cancer. Hematology. 2005;523-7. doi:10.1182/asheducation-2005.1.523

49. Neff LA, Karney BR. Gender differences in social support: a question of skill or responsiveness. J Pers Soc Psychol 2005;88 1:79-90. doi:10.1037/0022-3514.88.1.79.

50. Zebrack BJ, Gurney JG, Oeffinger K, Whitton J, Packer RJ, Mertens A, et al. Psychological outcomes in long-term survivors of childhood brain cancer: a report from the childhood cancer survivor study. J ClinOncol 2004;22 6:999-1006. doi:10.1200/ JCO.2004.06.148. 